\title{
Research on participatory teaching method of postgraduate education against the background of wisdom education
}

\author{
Suqin $\mathrm{Wu}^{1, \mathrm{a},{ }^{*},}$, Min $\mathrm{Lu}^{1, \mathrm{~b}}$ \\ ${ }^{1}$ College of management, North China University of Science and Technology, \\ Tangshan 063210, Hebei Province, China \\ a519344100@qq.com, b940519650@qq.com \\ ${ }^{*}$ Corresponding author
}

Keywords: Wisdom education, Postgraduate education, Participatory teaching, Implementation path.

\begin{abstract}
With the development of information technology, wisdom education emerges as the times require, which brings about new changes to the traditional educational mode and puts forward new requirements for the teaching mode of graduate education. This paper introduces the participatory teaching method into the graduate education under the background of wisdom education. Through the analysis of the connotation of the wisdom education and the theoretical basis of the participatory teaching method, this paper analyzes the integration of the wisdom education and the participatory teaching, and analyzes the application value of the participatory teaching method. From the perspective of classroom teaching, this paper puts forward the implementation path of participatory teaching method under the background of wisdom education.
\end{abstract}

\section{Introduction}

In recent years, with the development of information technology, into the era of Internet + , driven by a new generation of information technology such as large data, cloud computing and mobile Internet, the construction of intelligent city, intelligent community and intelligent campus has been set up in China. At the same time, there are also a series of intelligent projects, which provide a carrier for the construction of wisdom education. Therefore, wisdom education is an inevitable product of the development of information technology, and it gives a richer connotation than traditional education. As the main force of higher education, it is inevitable to extend wisdom education to postgraduate education. At present, many countries, cities and universities have adopted wisdom education as the strategic goal of social education and educational development.

\section{Background of intellectual education}

Wisdom education was first put forward by professor Max Van Manen in Canada in his book "teaching wisdom - the meaning of educational wisdom". In his view, wise pedagogy mainly explores how teachers use learners at the center and witty to exert their educational influence on learners [1]. Sternberg, a well-known psychologist in the United States, proposed the theory of wisdom balance. This theory advocates wisdom and teaches that education should teach students to think and solve problems in a smart way. At the same time, students should be trained to balance interpersonal, interpersonal, and human-environmental situations, and to cultivate the social sense of social responsibility of the students [2].

Domestic scholars generally believe that the term "wisdom education" comes from the "Great Learning Wisdom" proposed by Mr. Qian Xuesen. By summarizing his life, Mr. Qian Xuesen, an outstanding scientist of our country, has put forward the theory of great wisdom. This theory is guided by Marx's dialectical materialism, which is the essential difference between the wise theory of the past and the modern information network. The doctrine emphasizes the use of modern information networks, man-machine integration, and human-centered methods to gather experience of past, present, and international experience, knowledge, and wisdom [3]. 
Chinese scholars, Professor Zhu Zhiting [4], Professor Huang Ronghua [5], and Professor Jing Guoping [6] system research and explain the connotation of wisdom education. Wisdom education is to promote learners to think wisely and to learn wisely and improve their learning ability and become talented people through the construction of intelligent learning environment and the use of wisdom teaching method. That is to use appropriate technology to cultivate talents with intelligent ability through various intelligent means so that it can quickly adapt to the changes in the environment of society and life. It can also make appropriate adjustments in time to improve the participation of various social activities.

It can be seen that wisdom education is the key to solve the problem of how to educate learners and cultivate students' personality by focusing on students. The traditional education emphasizes the teaching mode of "teacher education and student learning", which is based on pure instillation of knowledge. The wisdom education is very different from that of it. Wisdom education takes information technology as the core carrier and emphasizes the positive interaction process of students' participation in the teaching process. In the era of Web2.0, students are no longer passive recipients, they are also the issuers and explorers of solutions. This teaching method needs to stimulate learning motivation through multiple orientation. It lets students contact learning entrance at any time and anywhere, provides rich learning resources, technical support and service teaching. In the traditional teaching process, the limitations on the classroom are limited, and teaching methods with the characteristics of intelligent teaching are integrated into the teaching process so as to realize the purpose of intelligent teaching and intelligent learning.

Participatory teaching is an innovative educational thinking and teaching mode. In the course of teaching, students play the leading role and take the initiative to participate in the whole process of teaching. Teachers also play a guiding role. It emphasizes the subjective initiative and enthusiasm of the students in the process of learning and gives full play to the students' personal potential. Under the background of wisdom education calling for wisdom teaching, the application of participatory teaching to graduate education can promote the students to change from passive learning to active learning. It give full play to students' initiative and innovation and enhance their students' participation. It will be more appropriate to the original intention of graduate education, which is of great importance to the level of higher graduate education.

\section{Participatory teaching method}

Participatory teaching is one of the teaching methods widely adopted by the international community of education and training. It started in 1960s in England [7]. Initially, participatory is a commonly used method in international project implementation, which has the characteristics of fully mobilizing the enthusiasm of project executors. Then, in the study of international aid projects, the sociological experts found that the aid project was successful only if the recipients were maximally involved in the aid project. Subsequently, the idea of "Participatory" is introduced into the field of education. A systematic and detailed participatory teaching method is gradually formed.

On one hand, the psychological foundation of the participatory teaching method is the motivation theory. For the teaching process, the motivation comes from two aspects: internal motivation and external incentive. The internal motivation comes mainly from the learning itself, and the external motivation comes from the educator. Only by combining intrinsic motivation with external motivation can we effectively encourage students to participate in the learning process autonomously and consciously. On the other hand, the psychological basis of the participatory teaching method is the expectation theory, and the expectation theory is that people always desire to meet certain needs and try to achieve a certain goal. This goal is expected when it is not yet realized, and it is an exciting force for the individual's motivation when the goal in turn. The size of the exciting force depends on the product of the target value (valence) and the expected probability (expected value). As for the teaching process, participatory teaching can make the students participate in the active teaching process and give full play to their subjective initiative so as to achieve the teaching goal. 


\section{The application value of participatory teaching method under the background of wisdom education}

It is conducive to innovate the teaching concept under the background of wisdom education. Education of wisdom emphasizes students at the center. To some extent, previous teaching methods failed to realize the original intention of wisdom education. Participatory teaching is a student centered teaching method, which accords with the requirement of intelligent education. The introduction of participatory teaching mode to explore the development of participatory teaching mode is conducive to the reform of teaching philosophy under the background of wisdom education.

It is conducive to give full play to the subjective initiative of teachers and students. The curriculum of public management has the characteristics of "strong theoretical and weak practice" in liberal arts. Students generally feel that knowledge is relatively boring, the enthusiasm of learning is not high, and the overall teaching effect is not good. Participatory teaching requires teachers and students to put forward higher requirements. For teachers, teaching preparation needs to be more fully before class. Teachers need to design different teaching links and improve students' participation according to the situation of students. Only when teachers are ready before class can they exert the advantages of participatory teaching and improve their teaching effect. For students, the participatory teaching can fully arouse the students' subjective initiative in the process of learning, make the students actively participate in the teaching process, give full play to the students' potential, make the students change from passive acceptance to active participation, and help students to master knowledge.

It is conducive to improve the quality of classroom teaching. In the past teaching process, teachers often impart knowledge to students through indoctrination, which is a common form in classroom teaching. In this kind of "full of full" teaching mode, teachers do not combine the characteristics of the students to carry out targeted teaching process design, while ignoring the students' learning ability differences and resulting in students' understanding of knowledge is not in place. This kind of teaching method is not targeted, although it can improve the teaching efficiency to a certain extent. It has sacrificed the quality of classroom teaching to a certain extent. With the use of participatory teaching methods, students will devote themselves to the course of classroom teaching. Students will think actively according to the problems set up by the teachers, then give their own views and share their views with others to deepen their understanding of the problems.

It is conducive to cultivate and improve students' comprehensive quality and practical ability. Since the theory of public management courses are not closely related to practice, the theory is especially strong, the content and design of teaching are too abstract, the practicality and maneuverability are weak. So the students can not apply the learned knowledge to practice well. The participatory teaching method allows students to participate in the process of knowledge learning. Participatory teaching method can visualize dull theories. It is easier to convey to students, so students are more receptive. The participatory teaching method can not only cultivate the students' ability to accept new things, but also cultivate the students' ability to think about the problem and promote the students' ability to express their expression. In short, participatory teaching method can enable students to exercise their abilities in all aspects so as to achieve wisdom education.

\section{The implementation path of participatory teaching method under the background of wisdom education}

The main classroom teaching designs of "problem participatory" teaching methods are as follows:

(1) First step: the creation of the situation, the problem leading

This step is led by teachers. According to the content and design of the course, the teacher sets up the classroom inquiry situation, throws out the problem, and gives a certain explanation to the problem so that the students can understand the set problems and guide the students properly. This can arouse students' enthusiasm and give play to their initiative. This part is the premise of the implementation of participatory teaching classroom design.

(2) Second step: problem thinking, cooperative exploration in group 
The students are required to enter the problem situation. Firstly, they need to think independently, look up the information on the related issues, gradually deepen their understanding of the problem, and gradually form their own views. Secondly, on the basis of independent thinking, students are asked to conduct group discussions, and members of the group collaborate to form a group's view on the problem.

(3) Third step: group discussion, sharing experience

After the completion of the second links, the groups have formed a preliminary view, and the teachers need to analyze the views of the groups and select the representative group opinions. The teams will show their findings to all the students and share their views. In this process, teachers should comment on the opinions of each group, evaluate the views of the students and make reasonable supplements, points and encouragement.

\section{Acknowledgement}

This research was financially supported by Reform project of postgraduate education in North China University of Science and Technology(Grant NO.P1701).

\section{References}

[1] V. M. Max, Teaching wit - the connotation of educational wisdom, Educational Science Press, 2001.

[2] R. J. Sternberg, Why schools should teach for wisdom: The balance theory of wisdom in educational settings, Educational psychologist, vol.36, pp. 227-245, 2001.

[3] X. M. Qian, Briefly talking about complex system and metasynthetic wisdom, Journal of Hechi University, vol.25, pp. 30-35, 2005.

[4] Z. T. Zhu, Leading the innovation and development of education information with the wisdom education, The Chinese Journal of ICT in Education, vol.9, pp. 4-8, 2014.

[5] R. H. Huang, Intelligent learning environment reinventing campus learning ecology, Basic education reform dynamic, vol.22, pp. 5-6, 2012.

[6] G. P. Jing, From the literal to the generalized wisdom education, Journal of Hebei Normal University (Educational Science Edition), vol.5, pp. 48-53, 2003.

[7] X. J. Bai, On the Application of Participatory Teaching Method in University Public Management Curricula, Journal of Huaihai Institute of Technology (Humanities \& Social Sciences Edition), vol.10, pp. 74-76, 2012.

[8] Z. G. Zhao. Study on the Reform of Wisdom Education to Promote the Innovation of Teaching, Computer \& Telecommunication, vol.1, pp. 20-21, 2017. 